\title{
有关房屋实预测面积差异的几点思考
}

郑卫强

北京市朝阳区房屋测绘事务所

DOI:10.32629/gmsm.v2i4.237

[摘 要] 随着我国房地产市场的日益飞速发展, “房屋面积如何计算” 问题成为大家关注的热点话题,特别对同一房屋在预测 面积和实测面积上的差异更为关心, 因为这涉及到千家万户产权人的切身利益, 也会影响到房地产业的发展甚至社会稳定。因 此切实做房产测绘工作, 必须严格控制房屋预测面积和实测面积的差异,使房产测绘行业能更好的发展。本文主要概述了房屋 实、预测面积差异产生的各种原因,基于差异分析,提出了减小房屋实、预测面积差异的办法,已便将差异降低到最小。

[关键词] 实测; 预测；差异；原因；方案

引言

随着我国房地产市场的日益飞速发展，“房屋面积如何 计算” 问题成为大家关注的热点话题, 特别对同一房屋预测 和实测面积的差异更为关心, 因为这涉及到千家万户产权人 的切身利益。

朝阳区, 隶属于北京市。位于北京市的东部, 西与东城 区、丰台区、海淀区相毗邻, 北连昌平区、顺义区, 东与通州 区接壤, 南与大兴区相邻, 幅员面积 470.8 平方千米, 是北京 市中心城区中面积最大的一个区。朝阳区辖 24 个街道, 19 个地区。

朝阳区对外交往活动频繁, 是北京市重要的外事活动 区。房屋寸土寸金, 使大家更为关注 “房屋面积如何计算” 这个热点话题。房屋实、预测面积差异的大小, 关系到产权 人经济利益, 如果差距较大, 很容易引发矛盾和冲突, 影响社 会稳定。因此切实做好实、预测工作, 对整个房产测绘行业 起着非常重要的实际意义。

笔者在实际工作中遇到了很多困难, 针对具体问题进行 了探索与实践, 现对房屋实、预测面积差异的常见问题加以 分析和处理。

\section{1 房屋实预测有关概念}

房产测量主要是采集和表述房屋和房屋用地的有关信 息, 为房产产权、产籍管理、房地产开发利用、交易、征收 税费, 以及为城镇规划建设提供数据和资料。房产测量的基 本内容包括房产平面控制测量、房产调查、房产要素测量、 房产图绘制、房产面积测算、变更测量、成果资料的检查与 验收等。

房屋建筑面积测算按照房屋的建筑状况, 可分为预测面 积和实测面积。

\section{1 房屋建筑面积预测}

房屋建筑面积预测是指依据规划批准后的设计图, 根据 《房产测量规范》、北京市地方标准《房屋面积测算技术规 程》规定, 对房屋的特征信息进行图上采集计算, 并同时生成 房屋物理数据, 出具房屋面积测算成果, 为房屋管理提供基 础数据的过程。

\section{2 房屋建筑面积实测}

房屋建筑面积实测是指房屋竣工后, 根据《房产测量规 范》、北京市地方地方标准《房屋面积测算技术规程》规定, 对房屋的特征信息进行实地采集计算, 并同时生成房屋物理 数据, 出具房屋面积测算成果, 为房屋管理提供基础数据的 过程。

\section{3 房屋建筑面积实测和预测的区别}

预测面积和实测面积本质的区别在于计算房屋面积的 数据采集来源不同, 前者根据规划批准后的设计图进行计算, 其面积用于签定商品房预售合同, 也可作为建筑工程预概算 方案比较的参考指标, 为房地产管理 (如规划、建设、开发等 管理) 提供参考数据; 后者根据房屋实地情况进行测算, 测算 结果用于房地产交易、租赁、抵押贷款、竣工验收、产权登 记等提供面积依据。

\section{2 房屋实测和预测面积产生差异的原因}

通常情况下, 房屋的预测面积和实测面积会有差异。产 生差异的原因有多种, 归纳为以下几点:

\section{1 设计图纸的变更}

一般情况下, 房地产开发企业应当按照规划部门存档备 案的房屋建筑施工图和建设工程规划许可证规定的条件建 设, 不得擅自变更。房屋预测主要是依据规划部门存档备案 的施工图纸进行的, 在图纸上进行数据采集、区分专有、共 用部位面积等。

但是随着城市建设的加快和房地产市场的变化, 在商品 房预测销售后, 房地产开发企业为适应外部环境的变化往往 会对建筑施工图纸进行变更。设计变更一旦得到批准并实施 后, 房屋建设随之发生变化。当设计变更影响房屋的尺寸大 小或使用功能时, 会对房屋的总面积或分户面积产生影响; 建筑尺寸的大小变更直接影响房屋的建筑面积; 公用部位的 变化影响到房屋公用建筑面积分推的变化, 从而对分户面积 产生影响。

\section{2 施工原因}

施工作业人员对设计图纸理解有偏差或不按建筑施工 图施工; 施工作业人员操作不规范或施工误差过大、现场环 
境发生变化, 使竣工后房屋尺寸不等于设计图上的尺寸。 2.3 测量误差

房屋建筑面积预测是依据规划批准后的建筑施工图, 采 集的计算数据是建筑施工图纸上的尺寸, 而实测的计算数据 采用现场测绘的实际测量值。正常的施工误差和测量误差也 可引起实测面积与预测面积存在少许差异。

2.4 技术原因

根据建设部《关于进一步加强商品房面积管理有关问题 的通知》精神, 各地纷纷实行测管分离, 将房产测绘推向市 场。房产测绘作为新兴行业, 目前存在着测绘机构综合素质 参差不齐, 测绘作业人员从业经验少、业务能力不强、流动 性大的问题, 对规范、政策、法规等理解不同, 容易造成面积 的测算失误。例如: 个别房产测绘单位从业人员对汽车坡道、 室外楼梯、建筑幕墙、中式房屋面积测算上存在从业经验少, 理解不足, 容易造成面积的测算失误。

\section{3 房屋实预测面积差异的解决办法}

正常情况下, 房屋的实、预测面积都会存在差异, 商品房 销售合同中也会约定允许存在 $\pm 3 \%$ 的差异, 但为了维护产权 人的利益, 也为了房地产业更好的发展, 在房屋开发建设及 房屋预、实测过程中应尽量减少因人为因素导致的房屋的 实、预测面积差异, 可以采取以下措施:

3.1 房屋开发建设过程中减少施工图变更和洽商

规划批准后的建筑施工图是建筑面积预测必须的测绘 依据, 其图纸是否准确直接影响到建筑面积预测的准确性, 应该检查预测图纸资料是否盖有规划部门档案查询章的全 套设计施工图。有些单位提供的是没有经规划部门核准的初 始设计图纸, 该图纸往往最后会变更, 不能作为预测使用。竣 工后房屋现状是建筑面积实测的重要依据, 要减少差异就需 要房屋建设过程中减少不必要的影响房屋面积计算的设计 洽商和变更, 若出现不可避免的对房屋面积有较大影响的洽 商和变更, 需重新办理规划施工图变更和预测手续。

3.2 加强施工作业人员管理, 确保减少人为因素加大的 施工误差

加强施工作业人员业务技术水平的考核和再培训, 严格 按照规定办事, 不断提高从业人员的业务水平, 确保施工人 员会看图, 能看懂图纸。

3.3 严格按照测绘作业规程, 加强数据采集的准确性和 规范性

在设计图上, 设计的尺寸有柱轴心尺寸、结构外墙尺寸、 净尺寸等, 这些情况与我们所需的计算套内面积的墙体中心 尺寸, 计算房屋建筑面积的墙外边沿尺寸有所不同, 都需要 经过换算, 所以, 在预测作业时, 要看清图上标注的是何部位 尺寸。

房屋实测数据的外业采集时, 草图记录必须在实地完成,
只可划改, 不可涂改。测绘形状规则的房屋时, 总要进行总尺 和分尺边长数据校核; 测绘不规则形状房屋时, 可使用仪器 实测该形状集合要素, 通过集合公式计算房屋建筑面积, 也 可实测该形状若干特征点或拐点的点位, 通过解析法计算建 筑面积。相同的套或单元应进行数据检核, 总长度或分段长 度应有多余测量数据。

3.4 严格资质管理, 建立信用档案, 加强测绘从业人员管理

首先, 对测绘机构进行资质审查。测绘管理部门要对当 事人 (产权人) 提交的房产测绘成果是否由已取得《房产测绘 资格证书》的测绘机构所提供进行严格的资质审查。没有取 得《房产测绘资格证书》的测绘机构所出具的测绘成果不得 用于房屋权属登记。

其次, 对测绘机构从业人员进行资质审查和培训。房产 测绘是一项技术性和专业性要求较高的工作, 为保证房产测 绘成果质量, 房产登记机关的测绘管理部门要对有资质的房 产测绘机构从业人员进行资质审查和系统培训, 充分了解从 业人员的资格、学历、知识结构和考评情况, 全面提升从业 人员的技术水平, 并定期进行专业房产知识的培训。培训合 格颁发上岗证后, 才能持证上岗从事房产测绘工作。加强行 业管理, 建立房产测绘单位、测绘技术人员信用档案, 对测绘 成果总体质量不高、出现严重错误的测绘单位、技术人员计 入信用档案, 影响其测绘资质及市场竞争。

\section{4 结束语}

商品房销售面积是商品房买卖的一个核心问题, 因面积 差异而引起的纠纷不断发生。因此, 非常有必要认真研究当 前商品房预、实测面积之间差异产生的原因和处理方法, 这 对于维护房地产市场的正常秩序, 保护当事人的合法权益, 都具有重要的现实意义。

\section{[参考文献]}

[1]何多兴,席险峰.面积测量的中误差分析[J].西南师范 大学学报(自然科学版),2018,(01):166.

[2]高向阳. 房屋预测面积与实测面积差异问题的处理 [J].中国地名,2018,(03):150.

[3]张鸿雁,杨雷主编, 中国房地产评论[M].东南大学出版 社,2018,(8):230.

[4]杨帆,危志远. 基于 GPS 卫星定位土地面积测量仪设计 [J]. 自动化与仪表,2019,34(1):50-52

[5]孟祥丽,刘一鸣.基于摄影测量技术的植物叶面积精 确测量方法研究 [J]. 西北林学院学报,2019,34(2):222-226.

[6]张鸿雁.中国房地产评论[M].东南大学出版社,2006:19.

\section{作者简介：}

郑卫强(1981--), 男, 北京市朝阳区人, 汉族, 本科学历, 房 产测绘工程师; 研究方向为房产测绘专业。 